\title{
PECULIARITIES OF TRAINING SPECIALISTS IN THE FIELD OF REGIONAL NATURE MANAGEMENT (ON THE EXAMPLE OF MARITIME REGION OF ARCTIC BASIN)
}

(C) 2018

\author{
Denisov Vladimir Vasilyevich, doctor of geographical sciences, professor, \\ chief researcher of Oceanography and Radioecology Laboratory \\ Murmansk Marine Biological Institute of Kola Scientific Center of Russian Academy of Sciences \\ (Murmansk, Russian Federation) \\ Mitina Elena Garisonovna, doctor of pedagogical sciences, professor of Natural Sciences Department \\ Svetlova Marina Vsevolodovna, candidate of geographical sciences, \\ associate professor of Natural Sciences Department \\ Murmansk Arctic State University (Murmansk, Russian Federation)
}

\begin{abstract}
The paper is devoted to the problem of training specialists in the field of regional environmental management. Environmental management in maritime regions of the Russian Federation has its own characteristics related to the inclusion of marine areas in the processes of natural resources extraction, protection and restoration of their reserves. The labor market of maritime regions requires bachelors and masters majoring in «Ecology and Nature» and «Geography», understanding of the maritime region as a special geosystem. Methodological development of the training model allows us to define the vector of students' professional competence development in the field of regional environmental management. The authors present their vision of this model, including justification of approaches, definition of principles for establishing the objectives, selection of content, organization of learning process and evaluation of results of training of ecologists and geographers in maritime region. The authors think that system and environmental approaches most effectively enable the training of students in activities of professional communities. Learning outcomes of students - ecologists and geographers within the framework of the proposed model meet the needs of the labor market of the maritime region, and may be the basis for the development of the professional standard «Specialist in the field of environmental management».

Keywords: regional nature management; maritime region; sustainable development; students training; competence approach; ecological and educational environment; professional development; professional standard; Federal state educational standard.
\end{abstract}

УДК 372.87

Статья поступила в редакцию 03.03.2017

\section{«АРТ-МАСТЕРСКАЯ» КАК ФОРМА ОРГАНИЗАЦИИ ХУДОЖЕСТВЕННО-ТВОРЧЕСКОЙ ДЕЯТЕЛЬНОСТИ ОБУЧАЮЩИХСЯ}

\section{(C) 2018}

Калинина Лариса Юрьевна, кандидат педагогических наук, доцент кафедры музыкального образования Самарский государственный социально-педагогический университет (2. Самара, Российская Федераици)

Аннотация. В статье охарактеризована инновационная форма организации учебной художественно-творческой деятельности школьников - «арт-мастерская». Автор обращается к обоснованию концепции «артмастерской» в контексте актуальных идей теории и практики художественного образования. Противоречие между содержанием творчества обучающегося в XXI веке и распространенными в практике традиционными формами приобщения детей к искусству может быть снято за счет структурирования занятий в соответствии с фазами творческого процесса. Материалы статьи представляют собой вклад в решение более масштабной проблемы ранней диагностики одаренности, так как, предположительно, данное качество личности проявляется чаще и заметнее именно в условиях художественно-творческого процесса. Сформулировано определение «арт-мастерской», выделены ее особенности: полихудожественный характер деятельности детей, продуктивной и направленной на постижение смыслов реальности через творческий опыт; привлечение элементов выразительности из «арсенала» современных композиторов, художников, поэтов. Подразумевается, что педагог способен воспринимать окружающее с непосредственностью ученика, направляя, но не ограничивая коллективное творчество. Проведенная работа дает возможность ориентировать учителей музыки, изобразительного искусства, педагогов дополнительного образования, студентов педагогического вуза на приобщение детей к творчеству в соответствии с их интересами, мировоззрением и способностями.

Ключевые слова: художественное образование; музыкальное образование; творчество учащихся; учебная художественно-творческая деятельность; синтез искусств; арт-композиция; арт-мастерская; постижение смыслов реальности через творческий опыт; современное искусство; мировоззрение современного школьника.

Постиндустриальное общество бросает человеку, живущему в нем, небывалые ранее вызовы. Стремительно меняясь, мир XXI века больше не поддается освоению как линейное, подчиненное конкретным правилам пространство. Быть готовым к новому, быстро ориентироваться в «хаосе» незнакомых обстоятельств - вот что требуется для успешной соци- ализации школьника. Формы учебной деятельности должны быть соответствующими, поэтому:

- отражать веяния времени и ценный педагогический опыт;

- обеспечивать реализацию возможностей художественно-творческой деятельности как средства личностного развития; 
- концентрировать профессиональный потенциал педагога в направлении метапредметных результатов обучения, интеграции дисциплин и рассмотрения каждого из видов искусства в контексте культуры как целого, согласно Федеральному государственному образовательному стандарту [1].

Так как понятие-источник, на которое мы опираемся в нашем исследовании, - «форма», необходимо уточнить его значение. Наиболее широкая трактовка формы акцентирует систему устойчивых связей внутри того или иного содержания, предмета [2]. В.В. Задерацкий замечает: «Смысловое значение [...] всегда оформлено [...] форма - не способ передачи замысла, а способ его существования» [3, с. 3]. То есть, чтобы ребенок научился свободно выражать свои идеи в материале искусства, форма организации его деятельности должна быть достаточно гибкой, открытой для использования привлекательных, доступных средств выразительности, соответствовать фазам творческого процесса [4].

«Арт-мастерская» является именно такой инновационной формой работы с детьми. Ее параметры обозначены нами в соответствии с актуальными запросами образовательной практики. Мы учитываем, что мировоззрение школьников за последние 1520 лет существенно изменилось [5, с. 4-5]. Современные дети неразлучны с мобильными телефонами, постоянно «зависают» в социальных сетях, им доступна самая разнообразная информация. При этом виртуальная реальность полна симулякрами, заменяющими истинные ценности (об этом пишет Е.В. Сухович, выражая точку зрения ряда исследователей [6]). В результате сочетание «энциклопедического» знания учеников, порождающего скепсис и отсутствие интереса к первоисточникам, с незрелостью эмоциональной сферы, «детскостью» поступков нередко затрудняют процесс педагогического общения. Применяя форму «арт-мастерской», учитель может преодолевать названные противоречия.

Охарактеризуем ее подробнее. Мастерская в традиционном понимании - это помещение, приспособленное для какого-либо производства, отделение большого предприятия; студия, ателье [7]. Также мастерской называют форму организации учебного процесса, в рамках которой группа обучающихся по плану, разработанному руководителем, выполняет реальные практические задания [8]. В зарубежных источниках термин «art workshop» употребляется, например, по отношению к изобразительному творчеству [9], игровой креативной деятельности ребенка [10], интеграции лингвистического и художественного обучения [11].

С учетом современных образовательных реалий, мы предлагаем такое определение: «арт-мастерская〉 - это форма организации продуктивной художественно-творческой деятельности обучающихся на основе технологии арт-композищии. Арт-композиционное творчество школьников предполагает, согласно психологическим закономерностям, четыре этапа творческого процесса: логический поиск, интуитивный поиск, вербализацию и формализацию найденного решения [4]. Поэтому форма арт-мастерской четырехчастна. Границы этапов и будут теми точками, на которых «действие» приостанавливается, меняет свой характер, а обучающиеся получают возможность понять, что открытие ими нового смысла в чем-то уже известном состоялось. Например, логический поиск (варьирование предложенного педагогом художественного материала в технике «опытов» современного автора) дает ребенку шанс осознать структурность текста любого произведения [12]. На этапе интуитивной работы возникают самые неожиданные и непредсказуемые ассоциаџии, иногда удивляющие самих детей. Вербализация приводит к более четкому пониманию ребенком-автором, что и зачем он создает. Итогом творческого процесса является воплощение задуманного в материале.

Арт-мастерская как форма организации учебной художественно-творческой деятельности:

- легко трансформируется с учетом предметной специфики учителями музыки, изобразительного искусства, литературы;

- приближает школьников к реальности в противовес виртуальным компьютерным «мирам»;

- содержит потенциал воспитания эстетического вкуса (как необходимого качества успешного человека XXI века) и интереса к исследованию мира через художественный опыт.

Основной принцип арт-мастерской - направленность на приобретение обучающимися навыков смыслопостижения, по примеру творческих «проб» современных авторов: музыкантов, художников, поэтов, драматургов, архитекторов, дизайнеров. Их современность мы понимаем как способность к инновационному художественному мышлению, не ограниченному «незыблемой» традицией, средствами выразительности только одного вида искусства.

O содержании деятельности, для которой артмастерская является, на наш взгляд, наиболее адекватной формой - арт-композиционного творчества, подробно сказано в опубликованных нами ранее статьях. Генетически арт-композиция связана с литературно-музыкальной композицией [13]. Общее между ними состоит в объединении разных видов искусства с целью предоставления ученикам возможности экспериментировать в области познания мира средствами искусства. Однако литературно-музыкальная композиция подразумевает, в первую очередь, формирование навыков «пристального вглядывания» в душевный мир человека $[14$, с. 4$]$, «узнавание самих себя в действии ... конструирования себя в пространстве пересекающихся искусств» $[15$, с. 6], создание из элементов литературы и музыки художественного целого, отвечающего эстетическим запросам общества [13, с. 112]. Для арт-композиции более характерна расстановка акцентов на моментах смыслопостижения окружающей действительности, напоминающих инсайт [16, с. 104-113].

Так как участниками арт-мастерской являются дети, то в своем представлении о новой форме работы педагогу надо «перевоплотиться» в ребенка, чтобы почувствовать, как вызвать его восторг, что «заставит задуматься, напрячь духовные силы. [...] Учитель [...] как бы занимает место учащегося в музыкально-образовательном процессе и пытается чувствами, мыслями учеников воспринять то, что будет происходить...» [17, с. 122].

Важно обратить внимание на целостность формы «арт-мастерской», составляющую ее преимущества 
перед другими средствами обучения. Педагоги-музыканты рассматривают возможность структурирования формы учебного занятия: на основе общей темы (Д.Б. Кабалевский), выстраивания последовательности отдельных видов деятельности учашихся как цельной и динамичной композиции (Н.А. Терентьева), ориентации деятельности педагога на предуготовленность ребенка к процессу творчества (Л.В. Школяр), акиентуации значения фрагмента занятия в сознании детей (Н.В. Суслова), создании «nартитуры» урока по аналогии с музыкальной партитурой (Н.Н. Гришанович) [18, с. 165-171]. Все эти идеи могут быть реализованы в форме «арт-мастерской». Главное - рационально планировать ход творческого процесса, оставляя место размышлениям, анализу, интуитивным находкам, вербализации замысла, его воплощению в материале. Реализовать все возможности данной формы можно во внеурочной деятельности учащихся (к примеру, музыкальная арт-мастерская с элементами театра).

Совместив приведенные в статье характеристики арт-мастерской с теми, которые обоснованы в научных работах современных исследователей, можно увидеть точку их совпадения: выделение в качестве кульминации занятия его этапа, на котором с высокой степенью вероятности детям удастся открывать собственные смыслы в искусстве и в окружающей действительности. Таким образом, размещение предполагаемых «озарений» во времени и пространстве занятия - важный момент планирования «артмастерской».

Арт-мастерская может быть самостоятельной единицей учебного процесса. В этом случае дети пробуют себя в художественно-творческой деятельности, а затем, выбирая вид искусства, который вызвал наибольший интерес, посещают внеурочные занятия по музыке, изобразительному искусству, хореографии, театру и т.д. Данная функция артмастерской особенно полезна, когда на занятие приходят первоклассники, у которых предпочтения в области внеурочной деятельности еще не определились.

Обучаясь в арт-мастерской, дети-авторы приобретают актуальные знания в области современного искусства, полихудожественные творческие навыки. Выбор материала необходимо тщательно продумать и осуществлять с учетом психофизиологических особенностей младших школьников или подростков (в зависимости от того, на какую возрастную группу рассчитан программный модуль). Если полный цикл обучения состоит из 16 занятий, то:

- на 1-м - 4-м обучающиеся узнают о возможностях работы с материалом. Наилучшим образом здесь применима музыка, классическая и современная, т.к. она всегда разворачивается во времени на основе логических связей, бывает носителем и выразительности, и изобразительности;

- занятия с 5-го по 8-е проводятся как своего рода «размышления», погружения, осознание сути явлений без их логического анализа [19] (например, конструирование арт-вариаций в материале изобразительного искусства);

- занятия с 9-го по 12-е предполагают работу со словесным материалом, лучше всего - поэтическим, так как слово в поэзии выражает информацию скон- центрировано и эмоционально (дети сочиняют хокку [20], синквейны [21] и др.);

- на 13-м - 16-м занятиях обучающимся предоставляется возможность оформления в художественном материале собственных идей (в условиях «полихудожественного хаоса» [22], то есть присутствия элементов разных видов искусства).

Программный модуль «арт-мастерская» целесообразно реализовывать в сотворчестве учителей музыки и изобразительного искусства, которые получают возможность наблюдать, как дети проявляют свою одаренность.

В ряде следующих публикаций мы обратимся к вопросам, связанным с апробацией формы арт-мастерской в практике педагогов Самары.

\section{Список литературы:}

1. Государственные образовательные стандарты общего образования [Электронный ресурс] // http:// edu.ru/db/portal/obschee/index.htm.

2. Кураев В.И. Содержание и форма [Электронный ресурс] // Большая советская энциклопедия. https://dic.academic.ru/contents.nsf/bse.

3. Задерацкий В.В. Музыкальная форма. В 2-х выпусках. Выпуск 1: учебник для специализированных факульт. высш. муз. учеб. заведений. М.: Музыка, 1995. 544 с.

4. Пономарев Я.А. Фазы творческого процесса (вместо введения) // Исследование проблем психологии творчества / отв. ред. Я.А. Пономарев. М.: Наука, 1983. С. 3-26.

5. Калинина Л.Ю. Синтез искусств в современном художественно-эстетическом образовании: монография. Самара: Изд-во «АРТЕЛЬ», 2017. 268 с.

6. Сухович Е.В. Символ, симулякр и виртуальная реальность как категории философии культуры: дис. ... канд. филос. наук. Волгоград, 2013. 153 с.

7. Константинов Г.Н. Мастерские [Электронный pecypc] // Высшая школа менеджмента. - http://mba. hse.ru/programs/mba/mba2_3.php.

8. Мастерская [Электронный ресурс] // Общий толковый словарь русского языка (Т.Ф. Ефремова, Д.Н. Ушаков, С.И. Ожегов и др.). - http://tolkslovar.ru/ m2399.html.

9. Chitrapatang [El. resource] // Chitrapatang art workshop. - https://plus.google.com/116941071829726275656.

10. Kristin. My Art Workshop [El. resource] // https://tripadvisor.ru/Attraction_Review-g33524-d1093865Reviews-My_Art_Workshop-Littleton_Colorado.html.

11. Srdjana Cvijetić [El. resource] // Art Workshop Lazareti: - http://zagreb.openinstitutions.net/arl.

12. Бахтин М.M. Вопросы литературы и эстетики. М.: Наука, 1975. 460 с.

13. Калинина Л.Ю. Роль литературно-музыкальной композиции в эстетическом воспитании учащихся детских музыкальных школ: дис. ... канд. пед. наук. Самара, 2001. 218 с.

14. Карпова Н.Л. Предисловие к книге Саркисян К.Б. «И слово в музыку вернись...» (музыкальнопоэтическая антропология): Для преподавателей и студентов по курсу «Мировая художественная культура». Самара: Изд-во СамГПУ, 2001. С. 3-6.

15. Торопова А.В. Предисловие к книге Саркисян К.Б. «И слово в музыку вернись...» (музыкальнопоэтическая антропология): Для преподавателей и 
студентов по курсу «Мировая художественная культура». Самара: Изд-во СамГПУ, 2001. С. 6-7.

16. Василевицкая О.В. Инсайт в структуре сознания // Сознание в актуальных измерениях: академический проект / отв. ред. Г.В. Акопов, Т.В. Семенова. Самара: ПГСГА, 2010. С. 104-113.

17. Алиев Ю.Б. Технология подготовки урока музыки // Методика преподавания музыки в общеобразовательных учреждениях: учебное пособие для студ. муз. фак. педвузов / Л.А. Безбородова, Ю.Б. Алиев. М.: Издательский центр «Академия», 2002. 416 с.

18. Абдуллин Э.Б., Николаева Е.В. Методика музыкального образования: учебник для студ. высш. пед. учеб. заведений / под общ. ред. М.И. Ройтерштейна. М.: Музыка, 2006. 336 с.

19. Фромм Э. Иметь или быть? // Величие и ограниченность теории Фрейда / Э. Фромм. М.: ООО «Фирма «Издательство АСТ», 2000. С. 185-437.

20. Горегляд В.Н. Хокку [Электронный ресурс] // Литературный энциклопедический словарь. - https:// literary_encyclopedia.academic.ru/7128/Хокку.

21. Виды синквейнов с примерами [Электронный pecypc] // Cinquain.ru: Синквейны. - http://cinquain.ru/ vidy-sinkvejnov-s-primerami.

22. Хаос [Электронный ресурс] // Философский словарь. - http://vslovare.info/slovo/filosofskiij-slovar/ haos.

\section{ART WORKSHOP AS A FORM OF STUDENT'S ARTISTIC AND CREATIVE ACTIVITY}

(C) 2018

Kalinina Larisa Yuryevna, candidate of pedagogical sciences, associate professor of Musical Education Department

Samara State University of Social Sciences and Education (Samara, Russian Federation)

Abstract. The paper describes an innovative form of organization of educational art-creative activity of students «art workshop». The author refers to the justification of the concept «art workshop» in the context of current ideas of the theory and practice art education. The contradiction between the content of student creativity in the XXI century and common in the practice of traditional forms of introducing them to the art may be withdrawn by the structuring activities in accordance with the phases of the creative process. Article submissions are a contribution to solving a larger problem of early diagnosis of giftedness, since supposedly this quality of the individual manifests itself more and more noticeable in terms of artistic and creative process. A definition of art workshop is given, its features are highlighted: polyart nature of children's activities, productive and aimed at understanding the meanings of reality through creative experience; engaging of elements of expression from the «arsenal» of modern composers, artists and poets. The implication is that the teacher is able to perceive the environment with immediate disciples, directing, but without limiting the collective creativity. This work makes it possible to orient teachers of music, fine arts teachers and teachers of additional education, as well as students of a pedagogical high school to making children be creative in accordance with their interests, abilities and their outlook.

Keywords: art education; music education; creativity of students; educational artistic and creative activity; synthesis of arts; art-composition; art-workshop; understanding meanings of reality through creative experience; modern art; modern student's world view.

УДК 378

Статья поступила в редакцию 13.01.2018

\section{КРИТЕРИАЛЬНО-ОЦЕНОЧНЫЙ АППАРАТ СФОРМИРОВАННОСТИ ПРОФЕССИОНАЛЬНО-ПРАВОВОЙ КОМПЕТЕНТНОСТИ БАКАЛАВРОВ СОЦИАЛЬНОЙ РАБОТЫ}

(C) 2018

Князева Анна Геннадьевна, старший преподаватель кафедры теории и истории социальной педагогики и социальной работы

Орловский государственный университет имени И.С. Тургенева (г. Орел, Российская Федерачия)

Аннотация. В статье поднимается вопрос об оценке сформированной в университете профессиональноправовой компетентности бакалавров социальной работы. Под профессионально-правовой компетентностью понимается профессиональное свойство выпускника по направлению «Социальная работа», способного эффективно решать профессиональные задачи в сфере правового регулирования социальной защиты населения. Уделено внимание актуальности этого профессионального качества у специалистов для современной России. Инструментом ее оценивания является критериально-оценочный аппарат, включающий мотивационный критерий (показатели: сформированность учебных, профессиональных мотивов, проявление интереса к праву); содержательно-когнитивный критерий (показатели: знание основ теории государств и права, основных отраслей российского права, объем, системность и осмысленность правовых знаний, знание нормативных актов правовых актов в сфере регулирования социальной защиты населения); креативно-деятельностный критерий (показатели: способность применять навыки и умения в решении профессионально-правовых задач, последовательность выполнения заданий, владение методами поиска, анализа и применения нормативных правовых актов в сфере социальной защиты населения); регулятивно-рефлексивный критерии (показатели: устойчивость в поведении, самооценка познавательной активности и последовательности выполнения заданий). Выполнен краткий обзор научных исследований по разработке критериев и показателей для оценки различных педагогических явлений. Автор останавливается на системном подходе в качестве методологиче- 